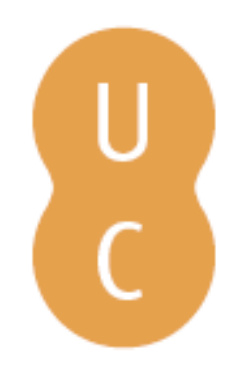

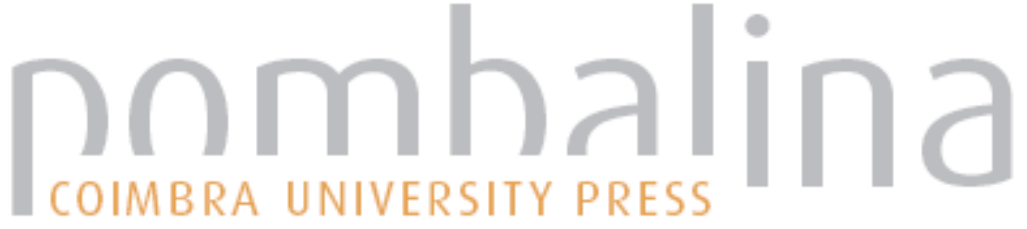

\section{Será a gestão por competências uma nova tendência na gestão de recursos humanos?}

\author{
Autor(es): $\quad$ Cascão, Ferreira; Keating, José \\ Publicado por: Imprensa da Universidade de Coimbra \\ URL \\ persistente: URI:http://hdl.handle.net/10316.2/32722 \\ DOI: $\quad$ DOI:http://dx.doi.org/10.14195/978-989-26-0452-7_9 \\ Accessed : $\quad$ 26-Apr-2023 10:20:34
}

A navegação consulta e descarregamento dos títulos inseridos nas Bibliotecas Digitais UC Digitalis, UC Pombalina e UC Impactum, pressupõem a aceitação plena e sem reservas dos Termos e Condições de Uso destas Bibliotecas Digitais, disponíveis em https://digitalis.uc.pt/pt-pt/termos.

Conforme exposto nos referidos Termos e Condições de Uso, o descarregamento de títulos de acesso restrito requer uma licença válida de autorização devendo o utilizador aceder ao(s) documento(s) a partir de um endereço de IP da instituição detentora da supramencionada licença.

Ao utilizador é apenas permitido o descarregamento para uso pessoal, pelo que o emprego do(s) título(s) descarregado(s) para outro fim, designadamente comercial, carece de autorização do respetivo autor ou editor da obra.

Na medida em que todas as obras da UC Digitalis se encontram protegidas pelo Código do Direito de Autor e Direitos Conexos e demais legislação aplicável, toda a cópia, parcial ou total, deste documento, nos casos em que é legalmente admitida, deverá conter ou fazer-se acompanhar por este aviso.

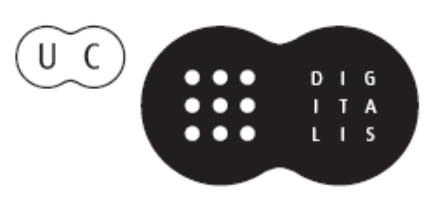




\section{A. DUARTE GOMES - ANTÓNIO CAETANO JOSÉ KEATING • MIGUEL PINA E CUNHA

\author{
Coordenadores
}

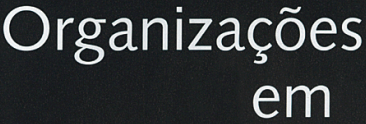

Transição

Contributo da Psicologia do Trabalho

e das Organizaçōes 
(Página deixada propositadamente em branco) 


\section{A. DUARTE GOMES - JOSÉ KEATING ANTÓNIO CAETANO - MIGUEL PINA E CUNHA Coordenadores}

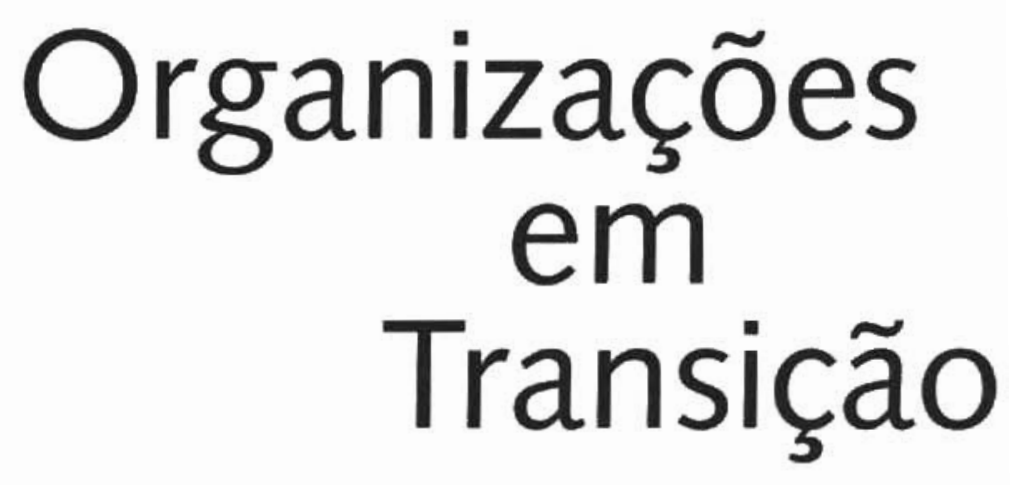

Contributos da Psicologia do Trabalho e das Organizações 


\section{COORDENACÁO EDITORIAL \\ Imprensa da Universidade de Coimbra \\ CONCEPÇÃO GRAFACA \\ António Barros \\ EXECUÇÃO GRAFICA \\ G.C. - Gráfica de Coimbra, Lda. \\ Palheira - Assafarge - Apart. 3068 \\ 3001-453 Coimbra Codex}

ISBN

972-98225-3-0

DEPOSITO LEGAL.

153435/00

(c) JunHo 2000. Imprensa da Universidade de Coimbra 


\title{
SERÁ A GESTĀO POR COMPETÊNCIAS UMA NOVA TENDÊNCIA NA GESTÃO DE RECURSOS HUMANOS?
}

\author{
Ferreira Cascão, josé Keating \\ INSTITUTO PORTUGUÉS DE ADMINISTRACÃOO DE MARKETING \\ UNIVERSIDADE DO MINHO
}

\section{INTRODUÇĀO}

Numa altura em que a literatura académica e as revistas de negócios falam cada vez mais nos desafios e na competitividade que as organizações contemporâneas enfrentam, a abordagem das competências é elevada a um papel central na estratégia e nas práticas de gestão de recursos humanos da organização. É neste contexto que surge a presente investigação, motivada. por um lado, pelo corpo teórico já significativamente desenvolvido e, por outro, pelos primeiros passos que se começam a dar no nosso país, nomeadamente através de algumas organizações que procuram testar esta abordagem. Uma das primeiras preocupações globais deste estudo foi perceber o impacto que os sistemas de gestão por competências têm nas práticas de gestão de recursos humanos da organização, pelo que, iremos neste artigo, analisar alguns dados recolhidos numa empresa que procura implementar a gestão por competências. Depois de uma breve revisão bibliográfica, apresenta-se a metodologia que suportou este estudo, a descrição do caso e alguns resultados observados. 


\section{A ABORDAGEM DAS COMPETÊNCIAS: HISTÓRIA E DESENVOLVIMENTO CONCEPTUAL}

O movimento das competências iniciou-se na América no final dos anos 60 e princípios dos anos 70. Nessa altura alguns autores da psicologia americana contestavam o interesse dos traços de personalidade (Ghiselli,1966; Mischel, 1968; McClelland, 1973). Argumentavam que os testes baseados nos traços da personalidade raramente mostravam correlações acima de .33 com a " performance" no trabalho, o que para eles tornava essas variáveis de valor questionável. Isto conduziu a uma certa ruptura com a análise tradicional do trabalho; enquanto esta definia o trabalho em termos de elementos funcionais e com base nos instrumentos de descriçāo, análise e qualificação de funçōes. típicos dos modelos tayloristas, a abordagem das competências propõe definir o trabalho em termos das características e comportamentos das pessoas que fazem bem o trabalho, devido sobretudo à necessidade em gerir a incerteza $e$ alguma imprevisibilidade dos contextos profissionais. $O$ crescimento desta metodologia é acelerado essencialmente através da Associação de Gestão Americana (A.M.A.), que promoveu o desenvolvimento de centros de avaliação com base nas competências e um programa de MBA (Master Business Administration). Estas aplicações e pesquisas da Associação conduziram à primeira publicação sobre a metodologia das competências (Boyatzis, 1982). Nesta obra, o autor propôs um modelo genérico de competências de gestão. em que a competência se equipara às características subjacentes de um indivíduo que têm uma relação causal com critérios de eficácia e/ou de realizaçāo superior num trabalho ou situação. Esta é uma abordagem comportamentalista em que o desempenho efectivo é um elemento central na competência e define-se como "alcançar resultados específicos. com acções específicas, num dado contexto". As competências nesta abordagem são motivações, traços de personalidade, auto-conceito, conhecimentos e habilidades. Na globalidade descrevem $\circ$ que $\circ$ individuo pode fazer e não necessariamente o que faz. A

216 abordagem comportamentalista parte da pessoa que executa $\circ$ trabalho de acordo com os resultados esperados e define o trabalho em função das caracteristicas de tais pessoas. Seguindo esta linha conceptual Spencer e Spencer(1993) publicaram uma pesquisa sobre modelos de competências efectuada em vários sectores de actividade(sector público, militar, indústria, educação e saúde). Argumentam também os autores que a "performance" individual é fortemente influenciada por um conjunto de competências forte- 
mente relacionadas com sucesso, devendo as organizaçōes aumentar o seu esforço para a identificação e desenvolvimento das competências adequadas nos indivíduos. Em França desenvolveu-se uma abordagem mais construtivista na medida em que a competência resulta de uma experiência profissional, em que é observada objectivamente a partir de um posto de trabalho e validada pela "performance" profissional (Guillet, 1994). Aqui a identificaçāo de competências surge a partir da análise dos disfuncionamentos organizacionais, os quais levam a um processo de aprendizagem e desenvolvimento das próprias competências pelos indivíduos.

Mas independentemente das suas orientações conceptuais, a abordagem das competências tem recebido grande atenção na literatura sobre gestão de recursos humanos e estratégia. Nesta última área têm-se observado várias versões do conceito, tendo todas exercido grande influência na operacionalização das vantagens competitivas da organização. Desde as "competências centrais" (Hamel, 1990) a "capacidades estratégicas"(Stalk, Evans e Schulman, 1992), à ligação entre estratégia e competências (Lado e Wilson, 1994) e à "capacidades organizacionais" (Ulrich e Lake, 1990; Lawler, 1992,1996), todos estes conceitos procuram promover a eficácia organizacional, a qual se torna efectiva quando a organização pode desenvolver o tipo de comportamentos que são necessários para lidar eficazmente com o seu ambiente de negócio. De qualquer forma tem-se verificado que a abordagem da gestão por competências tem sido utilizada de forma diferente pelas organizações. Por exemplo, diferentes firmas tendem a utilizar sistemas emocionalmente mais "quentes" em oposição a sistemas mais "frios" na gestão por competências (Lawler e Ledford Jr. 1997). Estes autores consideram a selecçāo como um sistema relativamente "frio" na medida em que afecta pessoas que ainda não se encontram na organização. Os sistemas de pagamento tendem a ser "quentes" na medida em que geram normalmente emoçōes fortes nos empregados. Formação e desenvolvimento, avaliação do desempenho, planeamento de pessoal e outros sistemas de recursos humanos situam-se entre estes dois pólos. Mas porque é que há firmas que utilizam sistemas mais "frios" ou mais "quentes"? Segundo os autores, os empregados respondem de diferente forma quando os sistemas "quentes" são envolvidos na gestão por competências. 


\section{GESTÃO POR COMPETÊNCIAS E EMPREGO}

Um dos aspectos principais da abordagem das competências é o relacionamento entre a gestão de competências e a estabilidade do emprego. As mudanças no mundo do trabalho têm sobretudo solicitado uma maior flexibilidade da força de trabalho. que inclui um movimento da explicitação do papel do trabalhador para a flexibilidade da designação e descrição do trabaIho e mudança de papeis. Estes factores sugerem que a natureza da participação irá mudar e tornar-se mais fluida. As fronteiras irão continuar obscuras entre quem está fora e dentro, por quanto tempo e sob que tipos de relacionamento. Bower e Siehl(1997) argumentam que os novos desenvolvimentos para o futuro da gestão de recursos humanos irão passar pela construção da coesão entre participantes que estão fisicamente separados, pela melhoria de competências mais "soft" (como por exemplo aumentar a flexibilidade dos trabalhadores) e pela reavaliação da importância duma extensa partilha de valores ou forte cultura organizacional. Neste contexto, as práticas da gestão de recursos humanos deverão ajudar as organizações a serem preferidas pelos empregados no mercado de trabalho, devendo estar também associadas a maior satisfação e mais lealdade dos clientes. Muitas organizaçōes ao avaliar as suas competências actuais versus as necessidades de futuro, concluem que os seus empregados não têm as competências adequadas. Perante as rápidas mudanças no perfil de competências, a organização sente-se mais tentada a "comprar" fora competências que não necessita permanentemente e não as procura desenvolver internamente. Isto levanta problemas ao nível do contrato entre os empregados e as organizações onde Bower e Siehl(1997) acreditam que a metáfora mais correcta para construir um efectivo contrato psicológico é o "empregado como voluntário", o que deverá levar à necessidade de construir relacionamentos de respeito entre participantes e organizações. Parece seguro que, com a abordagem das competên-

218 cias emergem novas solicitações aos empregados, as organizações procuram que os seus empregados se envolvam mais com os objectivos organizacionais: pede-se pois, uma mudança no relacionamento, um novo contrato psicológico, na medida em que as mudanças nas políticas e práticas organizacionais aumentam a violação dos mesmos (Rousseau, 1996).

Desenvolvido inicialmente por Levinson, Price. Munder e Solley(1962); Schein(1965), estes autores definiram o contrato psicológico como as expec- 
tativas acerca da obrigação recíproca que compõe uma relação de troca entre o empregado e a organização. Mais especificamente, definiram um contrato psicológico como o estabelecimento de crenças daquilo que cada parte deverá receber e, obrigar-se a dar, como troca pelas contribuições da outra parte. Essas obrigações são baseadas em promessas percebidas e não são necessariamente reconhecidas pelos agentes da organização (Lucero e Allen, 1994; McLean Parks e Schmedemann, 1994; Rousseau, 1989; Shore e Tetrick, 1994). Isto significa que o contrato psicológico é um construto muito extenso, que enquadra não apenas obrigações estabelecidas formalmente, mas também obrigações percebidas que resultam de significações implicitas. Para Rousseau (1995), o contrato psicológico é uma metáfora usada para descrever o relacionamento do empregado com a sua organização, que se tem movimentado em debates intelectuais muito ao nível da teoria das expectativas. A proposta da transformação do contrato é a criação de um novo contrato que se espera produzir envolvimento, criando expectativas positivas. Mas os indivíduos estão abertos à informação sobre novos contratos apenas em determinados momentos, um fenómeno psicológico referido como "processamento descontínuo de informação"(Rousseau, 1996). As pessoas frequentemente vêm aquilo que esperam ver, obtém informação apenas quando acham que precisam dela e ignoram grande quantidade de outra informação. Os processos cognitivos são preguiçosos e conservadores. As pessoas não trabalham duramente em novos contratos de mudança. As pessoas trabalham duramente nas suas próprias experiências. Quando os empregados não confiam nas suas organizações reagem com descrença aos contratos feitos pelos agentes da mudança e respondem com passividade: "Fica quieto que isto passará". A renegociação activa dos contratos requer que os empregados possuam uma boa compreensão da natureza do negócio, da sua estratégia, das condições do mercado e de indicadores financeiros. A mudança não pode ser legitimada se as pessoas não compreendem as suas razões. O presente e futuro contrato psicológico passará por um aumento do equilibrio e ajustamentos inevitáveis entre as partes. Este é um passo importante para se implementar qualquer projecto organizacional, nomeadamente a gestão por competências. Neste artigo apresentamos o inicio de um estudo de caso que procura investigar os aspectos descritos e discutidos neste enquadramento teórico. 


\section{METODOLOGIA}

Tendo em conta que o objectivo global do presente estudo é analisar o desenvolvimento dos recursos humanos a partir de um sistema de gestão por competências, bem como observar as associações existentes entre as competências e as práticas de gestão de recursos humanos, no sentido de iniciar a elaboração de um modelo conceptual susceptível de tornar compreensível esta realidade organizacional, adoptou-se a metodologia de estudo de caso. Esta opção começou por se justificar devido ao carácter exploratório deste estudo, ao insuficiente controlo do investigador sobre os processos em causa, bem como à ausência de evidência dos mesmos. Esta metodologia revelou-se também adequada na medida em que a característica fundamental do estudo de caso é o esforço para obter uma compreensão global de sistemas culturais de acção, os quais se referem ao conjunto de actividades inter-relacionadas e envolvidas por actores numa situação social (Feagin, Orum e Sjoberg, 1990). Por outro lado, as exigências e alguma inflexibilidade de outras formas de pesquisa acentuaram o interesse em suportar esta investigação na metodologia do estudo de caso, a qual começa por não exigir um número mínimo de casos ou casos seleccionados aleatoriamente (Yin, 1994).

Este estudo centrou-se à volta de uma grande organização. Embora os dados recolhidos até ao momento se relacionem apenas com uma unidade de análise, ir-se-á futuramente efectuar várias replicações, cujas unidades de análise serão semelhantes entre si, de forma a aumentar-se a confiança e robustez do quadro conceptual que se pretende desenvolver. A aleatoriedade das unidades de análise não é relevante, na medida em que o que se pretende é construir uma teoria e não generalizar resultados para determinadas populações (Yin, 1994). A isto o autor chama generalização analítica, que é também o que se pretende obter neste estudo quando se procurar constituir um quadro conceptual a partir de um conjunto particular de resultados. Após

220 as replicações, os resultados deverão ser aceites noutros casos similares. Isto constituirá a validade externa da metodologia. Foram utilizadas várias fontes de evidência, nomeadamente entrevistas semi-estruturadas, análise documental, observação directa e entrevistas de grupo. Para aumentar a confiança do estudo desenvolveu-se um protocolo do estudo de caso, o qual permitiu seguir com maior rigor determinados procedimentos sobretudo ao nível da recolha de dados. 
Entrevistas semi-estruturadas: As entrevistas são uma das fontes de informação mais importantes no estudo de caso. Os materiais da entrevista são documentos orais fornecidos por informadores em que através do seu discurso é possivel inferir factos relativos a um contexto que ultrapassa a situação de interacção estrita entre entrevistador e entrevistado(Maroy, 1995). Neste estudo não se partiu de nenhum quadro de referência, mas foi-se desenvolvendo à medida que se íam realizando as entrevistas. Estas assentaram basicamente num guião constituído por questões abertas e relacionadas com os objectivos da investigação. Essas questões serviram apenas para que o entrevistador tivesse sempre presente os objectivos do estudo e permitiram conduzir o entrevistado para comentários acerca de determinados acontecimentos relacionados com a gestão por competências e as práticas da gestão de recursos humanos. $O$ grau de aprofundamento das respostas teve sobretudo em conta a relevância e o envolvimento que o entrevistado evidenciava na situação. Procurou-se também nas entrevistas confirmar ou infirmar dados obtidos através de outras fontes de informação, nomeadamente de outros entrevistados, da observação directa e da análise documental. As entrevistas foram gravadas, para o que se pediu previamente autorização ao entrevistado. Foram posteriormente transcritas na íntegra.

Entrevistas de grupo: A utilização desta técnica de recolha de dados surgiu num momento em que foi necessário entrevistar um conjunto de pessoas num curto espaço de tempo, não sendo exequível a sua realização através de entrevistas individuais. Esta situação permitiu ouvir diferentes vozes ao mesmo tempo sobre a gestão pelas competências e as práticas da gestão de recursos humanos. Steyaert e Bouwen (1994) consideram as entrevistas de grupo com muito interesse para recolher dados nas organizações, tendo também muita tradição na pesquisa em Marketing e estudos de opinião, sendo normalmente designadas por "focus group". É um grupo tipicamente composto de seis a dez participantes que são seleccionados porque têm certas características em comum que estão relacionadas com os tópicos do estudo (Morgan, 1991; Krueger, 1994). A constituição dos grupos nesta investigação seguiu estes critérios, tendo-se formado grupos da mesma área funcional (área comercial), de funções semelhantes e da mesma zona geográfica. Ou seja, os grupos de discussão foram conduzidos várias vezes com tipos semelhantes de participantes para identificar opiniões e relações nas percepções. Procurou-se planear cuidadosamente a discussão de forma a obter percep- 
ções acerca da gestão por competências e gestão de recursos humanos. As discussões desenvolveram-se pelos participantes de forma frequentemente agradável, sendo conduzidas por dois entrevistadores. Estes íam convidando os membros do grupo a falar das suas histórias relativamente aos tópicos referidos e preparados previamente. As opiniões e percepções evidenciadas tanto estavam alinhadas como contrastavam com outras previamente referidas. Estas discussões de grupo permitiram estabelecer diferenças e semelhanças entre os diferentes participantes e tornou mais visível a dinâmica das perspectivas sobre a gestão por competências. Seguindo os conselhos de Steyaert e Bouwen(1994), as entrevistas de grupo seguiram uma metodologia aberta em que as pessoas íam contando as suas histórias em vez de responderem a questões. Outro nível de condução das entrevistas foi orientado para o processo, com especial atenção às relações de comunicação que se foram desenvolvendo. Existiu uma preocupação em observar se todos os participantes se mantinham activos na discussão, se o tempo estava a ser respeitado, se os participantes se estavam a desviar do tema ou se existia alguma "quebra" no grupo. Aqui também foi pedido aos grupos autorização para gravar as entrevistas, sendo posteriormente transcritas.

\section{Análise das entrevistas}

A avaliação dos dados obtidos e dos que se vierem a obter neste estudo de caso irá consubstanciar-se na integração da informação obtida nas várias unidades de análise a efectuar, de acordo com a recomendação de Yin(1994). Estes primeiros dados obtidos foram analisados no sentido de começar a identificar os principais problemas inerentes ao desenvolvimento e implementação do modelo de gestão por competências e as suas implicações ao nível das práticas da gestão de recursos humanos. Esta análise seguiu uma codificação aberta sugerida por Strauss e Corbin(1998). A partir de cada entrevista procurou-se responder às perguntas: " $\mathrm{O}$ que é que se passa aqui? $\mathrm{O}$ que é

222 que há de semelhante ou diferente nesta entrevista? Qual é a ideia principal que emerge daqui?" Como estávamos a desenvolver um estudo exploratório, a análise efectuada não construiu de forma exaustiva categorias com as respectivas propriedades e dimensões. $O$ processo de codificação foi terminado quando permitiu não só começar a compreender alguns problemas inerentes às questões da investigação, mas também levantar novas questões e, consequentemente, ajustar a orientação do estudo. 


\section{I. PROTOCOLO DO ESTUDO DE CASO}

Dado que a proposta global deste estudo é compreender até que ponto as novas abordagens da gestão por competências irão alterar as práticas da gestão de recursos humanos e acrescentar valor à organização, procurou-se efectuar o estudo numa empresa que estivesse envolvida num processo de desenvolvimento e implementação deste modelo. Iniciaram-se então os contactos com uma organização que se encontrava numa fase inicial de desenvolvimento do modelo de gestão por competências, apresentaram-se os objectivos da presente investigação aos responsáveis pelo projecto e, após acordo da direcção geral de recursos humanos, iniciou-se o presente estudo de caso. Procurou-se nesta altura transmitir a importância do acesso do investigador às diferentes fontes de informação, nomeadamente a documentos e a informadores com diferentes posições hierárquicas e funcionais na empresa, bem como a diferentes áreas geográficas de actuação da empresa. As principais fontes de informação foram entrevistas individuais e em grupo, sendo que, à medida que elas íam sendo realizadas foram-se fazendo pequenos ajustamentos aos tópicos abordados, tendo em conta as respostas dadas na entrevista anterior. A função exercida pelo interlocutor também influenciou os ajustamentos que se foram fazendo ao longo do processo de recolha de dados. A duração das entrevistas individuais variou entre os quarenta e cinco e noventa minutos e as entrevistas de grupo demoraram cerca de duas horas.

$\mathrm{Na}$ altura que se iniciou a recolha de dados, a organização encontrava-se numa fase de comunicação interna dos objectivos do projecto. Para isso, os responsáveis do projecto contactaram directamente com todas as suas chefias através de reuniões que desenvolveram em todo o país. Esta fase foi também o primeiro momento da recolha de dados deste estudo. De seguida, o investigador concentrou a sua recolha de informação apenas numa área geográfica (grande Lisboa), a qual foi considerada uma unidade de análise deste caso e sobre a qual se produziram alguns resultados que ırão ser apresentados.

\section{Questões da investigação}

- Quais as razões que levaram a empresa ao desenvolvimento conceptual e implementação do modelo de gestão por competências?

- Quais as primeiras implicações e consequências do modelo ao nível das práticas ou subsistemas da gestão de recursos humanos? 
- Que tipo de relacionamento ou envolvimento se está a desenvolver entre a organização e os trabalhadores através deste modelo?

- Quais as expectativas dos trabalhadores e dificuldades com a implementação do modelo de gestão por competências?

\section{Fontes de informação}

Entrevistas individuais e de grupo.

Actores: Responsável pelo projecto de gestão por competências, responsáveis e colaboradores de recursos humanos, responsáveis de zona/negócio, chefias intermédias e operacionais.

As entrevistas desenvolveram-se sequencialmente pelo responsável do projecto, responsáveis de recursos humanos, responsáveis de zona/negócio, chefias intermédias e operacionais. $O$ interesse em iniciar as entrevistas pelos recursos humanos teve sobretudo a ver com a divulgação interna da investigação que eles fizeram a seguir de forma a aumentar o acesso do investigador.

Estrutura geral das entrevistas: explicação do projecto de investigação, funções, práticas de gestão de recursos humanos, projecto das competências, papel do entrevistado quer nas práticas quer nas competências, clima da empresa.

Entrevista com responsáveis pelos recursos humanos: descrição das práticas de gestão de recursos humanos, função recursos humanos na empresa, características dos recursos humanos, modelo da gestão por competências (origem, concepção, implementação adesão, expectativas, dificuldades e mudanças).

Entrevista com responsável de zona/negócio: estrutura da zona, organização geral do trabalho, estratégias, politicas de gestão, função recursos humanos, características dos recursos humanos, projecto das competências (concepção, implementação, adesão, expectativas, dificuldades e mudanças).

Colaboradores dos recursos humanos: detalhes dos procedimentos relativos às práticas de gestão de recursos humanos, projecto das competências

224 (implementação, adesão, expectativas, dificuldades e mudanças).

Chefias intermédias: organização do trabalho, utilização dos recursos humanos, práticas de gestão de recursos humanos, projecto das competências (conhecimento, implementação, adesão, expectativas e mudanças).

Operacionais: detalhes da aplicação das práticas da gestão de recursos humanos, satisfação/insatisfação, conhecimento e expectativas com o projecto das competências. 
Observação: as observações foram efectuadas em momentos antes e após as entrevistas, mas também realizadas em momentos específicos e preparados para o efeito. Procurou-se observar:

- Momentos de comunicação e discussão do projecto

- Condições de trabalho

- Funcionamento de suportes de apoio ao desenvolvimento do projecto

- Relacionamento interpessoal, hierárquico e com clientes.

Documentos

- Organigrama

- Manual de apresentação da empresa

- Catálogo de produtos/serviços

- Fichas e exemplares de instrumentos de gestão de recursos humanos/ /gestão por competências

- Balanço social

- Relatórios relevantes.

\section{Descrição do caso}

Apresentaçõo da empresa

O caso em análise refere-se a uma grande empresa nacional e um dos maiores empregadores do nosso país. Por razões de alguma confidencialidade, iremos neste momento, fazer apenas uma caracterização muito genérica da organização, relevando, sempre que possível, os aspectos mais pertinentes tendo em conta o nosso objecto de estudo. Esta empresa actua em todo o território nacional, no sector terciário. Pretende implementar o modelo da gestão por competências em todas as regiōes. A sua actividade reveste-se de forte componente comercial e envolve um sector tecnológico de grande desenvolvimento actual e, previsivelmente, de futuro.

O objectivo da presente investigação é analisar toda a organização através de um estudo longitudinal suportado em várias unidades de análise, às quais correspondem diferentes regiōes geográficas. Este trabalho inicial concentrou-se na região de Lisboa.

\section{Estrutura organizacional}

Neste momento, em consequência de um processo de reestruturação relativamente recente, a empresa encontra-se dividida em duas grandes 
zonas(zona norte e zona sul). Cada zona depende das respectivas direcções gerais, as quais dependem da administração. A organização possui cinco direcções gerais: financeira, recursos, infraestruturas, negócios pessoais e negócios empresariais. Cada uma destas direç̧ões gerais possui vários departamentos com responsabilidades várias inerentes à área em causa. Existem ainda vários gabinetes e direcçōes de assessoria à administração.

A empresa tem vindo nos últimos anos a seguir uma política de racionalização de efectivos essencialmente através de mecanismos de antecipação de aposentação, pré-reformas e rescisão do contrato por mútuo acordo. Em paralelo a esta redução do efectivo, a empresa tem procurado desenvolver uma política de requalificação dos trabalhadores através de formação profissional e da admissão de quadros com nível de qualificação superior. Em finais de 1997, as idades e antiguidades médias situavam-se nos 42,5 e 18,9 anos respectivamente. $O$ nível de habilitações nesta altura distribuía-se também da seguinte forma: licenciatura(15\%); bacharelato(4\%); $10^{\circ} / 1 \mathrm{I}^{\mathrm{a} a n o}(17 \%) ; 9^{\circ}$ ano(26\%); $6^{\mathrm{a}}$ classe(13\%) e até à $4^{\mathrm{a}}$ classe(25\%). Ou seja, $64 \%$ dos trabalhadores possuíam habilitações iguais ou inferiores ao $9^{\circ}$ ano de escolaridade.

\section{Estratégia organizacional}

Através de vários estudos de mercado efectuados, a empresa verificou que o mercado está carente de várias mudanças no seu sector de actividade. Isto levou a administração a solicitar ao gabinete de estudos da direcção de recursos humanos o desenvolvimento de um sistema de gestão de recursos humanos que sustentasse a estratégia da empresa num quadro de elevada turbulência. Os objectivos globais da estratégia passavam por consolidar uma cultura de cliente e converter a empresa em sinónimo de excelência através de:

- assegurar que toda a criatividade da empresa chegue ao mercado;

- continuar a formar o pessoal nas novas capacidades requeridas pelo negócio;

- acabar com as barreiras à mudança;

- desburocratizar a organização para se concentrarem em acções dirigidas aos clientes:

- combinar o empenho da empresa com as capacidades diferenciadas para manter a liderança; 
- aproveitar as sinergias entre as diversas áreas de negócio da empresa como base de diferenciação e

- evoluir para uma estrutura de custos competitiva e flexível.

A concorrência, internacionalização e tecnologia eram os factores chave destas orientações estratégicas. A empresa pretendia apostar na orientação para o cliente, na eficiência/eficácia, em novos serviços/novos produtos e soluções integradas, dando ênfase às áreas de marketing/comercial, sistemas de informação e tecnologia estratégica. Foi então determinado o desenvolvimento de um programa para adequar, atrair e vincular os talentos em função das necessidades empresariais e em diálogo social alargado. Desse programa nasceram directrizes estratégicas para o desenvolvimento dos recursos humanos, nomeadamente:

- adequação dos recursos humanos a um ambiente de competitividade;

- desenvolvimento de um sistema de carreiras adequado a um ambiente de grupo e internacionalização;

- desenvolvimento de sistemas de compensação motivadores;

- formação centrada no desenvolvimento de competências chave em ambientes competitivos:

- conquista, adesão e empenho dos trabalhadores para a nova "atitude empresarial", comunicando a visão e os valores a partilhar.

\section{Diagnóstico organizacional}

A empresa procurou desde $o$ início envolver toda a organização na concepção e desenvolvimento deste programa. Para isso, envolveu directamente cerca de 200 pessoas ( 157 interlocutores que representaram todas as áreas de actividade, 1 I pessoas da equipa de projecto da direcção de recursos humanos, 5 consultores e cerca de 20 representantes de organizações sindicais).

A operacionalização do programa começou com a realização de um diagnóstico sobre a adequação dos recursos humanos às orientações estratégicas da empresa. Neste diagnóstico verificou-se:

- falta de visibilidade das novas competências requeridas;

- desconhecimento das competências existentes e do potencial interno de desenvolvimento:

- plano de recursos humanos de índole estritamente quantitativa;

- passividade das pessoas face à obsolescência das competências detidas;

- nível médio de habilitações muito baixo; 
- elevados níveis de idade e de antiguidade médias;

- elevado número de trabalhadores em categorias não directamente ligadas ao negócio(cerca de II,3\%).

Ao nivel da evolução profissional dos trabalhadores verificou-se que existia uma gestão massificada, com carácter igualitarista e administrativo, evolução assente quase em exclusivo no decurso do tempo, posicionamento na carreira independente da real valia para a empresa das competências detidas, ausência de estímulos ao desenvolvimento individual de competências e elenco de categorias desajustado da realidade actual. Das categorias consideradas (foram excluídos técnicos superiores e chefes de serviço), $43 \%$ progridem até ao último nível apenas com base na antiguidade. $25 \%$ progridem até ao penúltimo nível por antiguidade, 32\% têm, no final do percurso de progressão, dois ou mais niveis por nomeação. Em média, um trabalhador (não quadro) tem progressões automáticas garantidas por um período de 23 anos.

Relativamente à remuneração observou-se um peso reduzido nas remunerações variáveis, leques salariais muito compactos, ausência de relação entre a retribuição, o valor das funções/competências detidas, a qualidade do desempenho e os resultados obtidos, progressivo agravamento dos níveis de motivação e encargos fixos a níveis já preocupantes com tendência a agravar, - que estava a conduzir a um impacto negativo ao nível da capacidade competitiva. Mesmo sem aumentos na tabela salarial e diuturnidades, a massa salarial aumentaria $0,9 \%$ em resultado da dinâmica da antiguidade. A remuneração ligada a desempenho e resultados abrangia cerca de $9 \%$ de trabalhadores das áreas comerciais, havendo predominância de remunerações variáveis não directamente ligadas a sistemas de objectivos e, portanto, menos controláveis. Ao nível dos sistemas de avaliação, observou-se a inexistência de um sistema formal aplicável à generalidade da população, desconhecimento das competências existentes, dificuldade em orientar o desenvolvimento individual e em

228 optimizar o esforço em formação, pouca clareza de critérios na distinção de desempenhos e diluição da responsabilidade das chefias na gestão e desenvolvimento dos colaboradores.

É neste contexto que emerge o sistema de Gestão de Recursos humanos por competências, o qual é apresentado com vantagens mútuas para o trabalhador e a empresa porque: facilita a orientação profissional, potência a gestão individual de carreira, traz maior flexibilidade à capacidade de acom- 
panhamento da mudança de contexto e de estratégia,às competências e níveis de proficiência e torna a política retributiva mais ajustada. Transmite ainda melhor visibilidade do papel na empresa e de chances de desenvolvimento profissional.

\section{O modelo de gestão por competências}

A empresa definiu o conceito de competência como "os conhecimentos, capacidades, traços de carácter, atitudes, valores, ou seja, qualquer característica individual que possa ser medida com fiabilidade e ser relacionada com um desempenho eficaz numa actividade profissional." É uma definição muito próxima de McClelland (1973); Boyatzis (1982) Spencer e Spencer (1993) já referenciados neste estudo, que procura transmitir a ideia de que a competência é tudo aquilo que no indivíduo pode levar a elevados desempenhos. Dentro deste quadro conceptual, a empresa considera ainda três grandes variáveis: valores, qualidades profissionais e competências (em sentido estrito). Os valores seriam os factores críticos de sucesso para incrementar e consolidar a capacidade competitiva da empresa; atitudes orientadoras dos comportamentos e forma de estar dos trabalhadores da empresa. As qualidades profissionais seriam os traços de carácter e capacidades pessoais que se expressam genericamente em comportamentos interpessoais e na forma de responder a situaçōes concretas. As competências (em sentido estrito) seriam conhecimentos adquiridos sobre uma determinada matéria e a capacidade de os pôr em prática no decurso da actividade profissional segundo os parâmetros exigidos. Foram depois definidos os níveis de proficiência das competências, que se traduzem em patamares progressivos de exigência que reflectem diferenças no exercício das competências. Desta forma, o modelo desenhava o perfil da função (conjunto de competências e respectivos níveis de proficiência necessários para o desempenho da função).

A partir daqui este sistema iria permitir desenvolver alguns princípios de evolução profissional: desenvolver competências como critério básico de evolução profissional na função e entre funções, criar cenários de orientação do esforço de desenvolvimento pessoal de cada trabalhador, em função das necessidades previsíveis da empresa, privilegiar a gestão individual da evolução, em detrimento do tratamento massificado e demarcação nítida da evolução profissional de preocupações estritamente remuneratórias. 
Ao nível do sistema de retribuição, pretendia-se que a evolução da remuneração base reflectisse o desenvolvimento profissional do trabalhador, que traduzisse a importância da função desempenhada e se construíssem instrumentos susceptíveis de remunerar o desempenho e contributos dos trabalhadores para os resultados da empresa.

O sistema de avaliação também deveria ser facilitador do desenvolvimento profissional e da motivação, ligado aos objectivos da organização, da equipa e do indivíduo, equitativo e fiável, periódico e actualizável, simples e eficiente.

Articulação geral do sistema

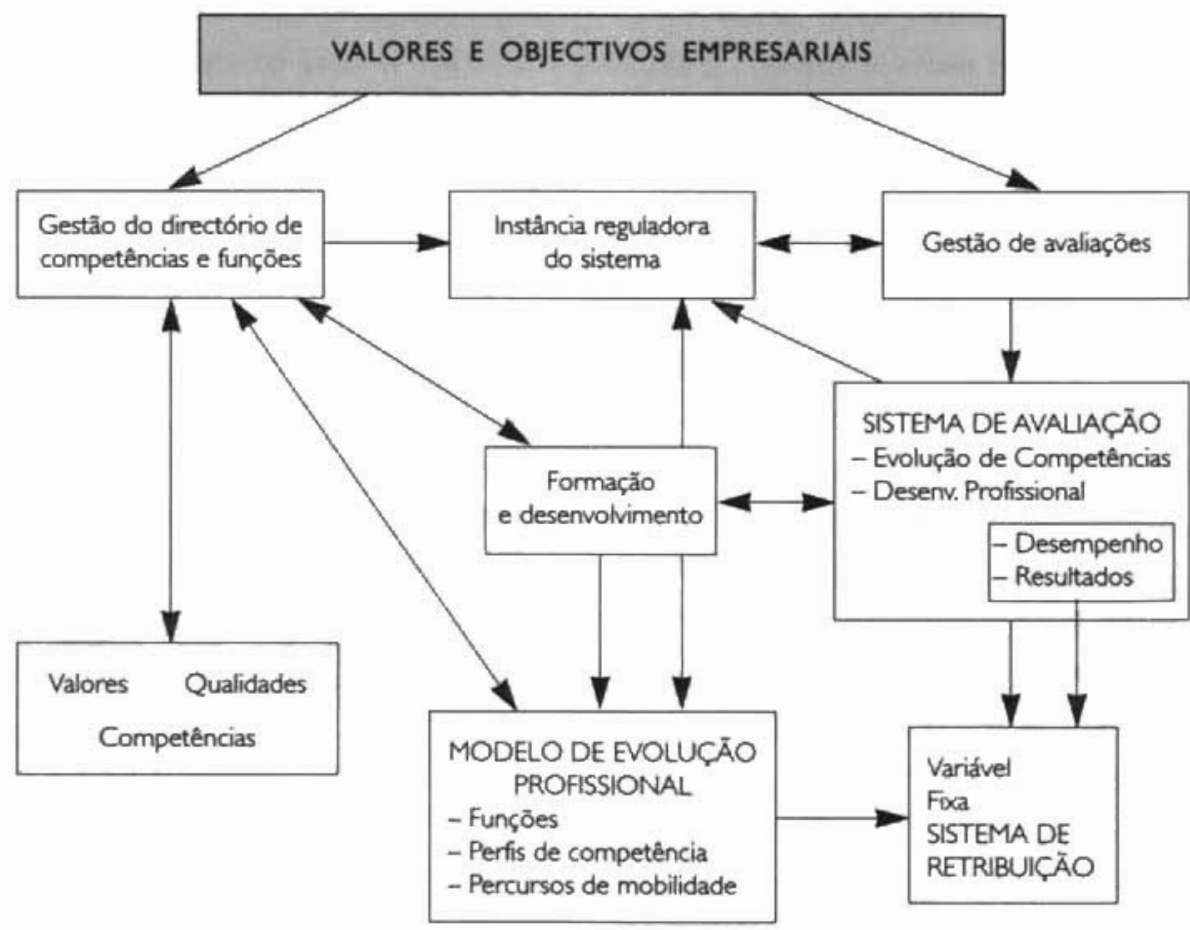

Figura I - Articulação geral do sistema

Como se pode observar na figura 1, o sistema concebido parte de valores e objectivos empresariais para a gestão do directório de competências e funções, bem como para a gestão de avaliações. Será a gestão do directório 
de competências que irá permitir a formação, o desenvolvimento e a evolução profissional dos colaboradores, o que será acompanhado pelo sistema de avaliação. Em consequência, deverá surgir um sistema de retribuição com uma componente fixa e outra variável. $\mathrm{O}$ desenvolvimento deste modelo será apoiado por uma instância reguladora que fará os ajustamentos necessários à sua implementação.

\section{Plano de implementação}

Desde o início que a empresa teve consciência de que o êxito do sistema proposto dependeria sobretudo do modo como se operasse a transição entre diferentes perspectivas da gestão, das direcções sindicais e dos próprios trabaIhadores. Isto levou a empresa a efectuar um sério esforço de diálogo social, procurando alcançar acordos quanto à globalidade do sistema ou, pelo menos, quanto ao princípio do voluntariado. Nesta altura era pois importante divulgar o novo sistema e envolver a organização na implementação.

A metodologia seguida para iniciar este processo foi a realização de reuniões com todas as chefias da organização em várias regiões do país, onde eram comunicadas as razões e os objectivos do projecto e se discutiam algumas questões inerentes à mudança pretendida . Embora o projecto fosse, na globalidade, aparentemente aceite, levantaram-se no entanto, algumas questões por alguns dos participantes que indiciaram algumas resistências, as quais pareciam derivar da concepção de outros projectos que depois não foram implementados e do desconforto que a alteração de algumas práticas de gestão de recursos humanos poderia vir a causar. Mas iremos de seguida aprofundar a discussão do caso, onde serão apontados os principais constrangimentos observados.

\section{DISCUSSÃO DO CASO}

\section{Dificuldades com as práticas actuais}

A partir dos dados obtidos foi possível observar algumas dificuldades que os vários níveis da gestão enfrentam na aplicação de algumas actividades para os seus recursos humanos. Ao nível do recrutamento e selecção foi evidenciada uma grande preocupação pelo facto de estarem a sair da empresa muitos trabalhadores competentes e depois, com as condiçōes que a empresa ofe- 
rece actualmente, não conseguem recrutar e seleccionar pessoas com o mesmo nivel de qualificações e competências.

$\mathrm{Na}$ formação os constrangimentos mais notórios prendem-se com a adequação/inadequação da formação às reais necessidades dos trabalhadores para desempenharem bem o seu trabalho. Parece ter sido relativamente frequente que quem ia à formação era quem tinha maior disponibilidade de tempo e não quem dela necessitava realmente. Ou então a escolha dos cursos que existiam no catálogo tinha como critério a aprazibilidade do local da sua realização. Existia uma certa cultura que incentivava as pessoas a inscreverem-se nos cursos que mais lhes interessava sem grandes fundamentos nas necessidades organizacionais. Era um sistema de formação relativamente inconsequente, em que a própria avaliação não parecia estar fundamentada em processos rigorosos e orientados para resultados organizacionais. Ou seja, foi claramente observado um grande consenso à volta de fortes desajustamentos entre a formação que a empresa tem disponibilizado e as suas reais necessidades. $E$ isto parece ser agravado pelo facto da empresa ter alguma tradição a investir fortemente na formação. Aparentemente esta é uma das actividades dos recursos humanos que parece ter grande receptividade por parte dos trabalhadores para se alterar a forma como se processa a sua aplicação. De referir que foi exactamente por aqui que o projecto das competências começou a ser implementado.

Em termos da avaliação do desempenho observou-se também algum descontentamento pelo facto dos trabalhadores não terem alguma recompensa com base na produtividade dos respectivos departamentos, bem como a partir do cumprimento de objectivos. Sobre isto têm sido feitas algumas experiências esporádicas e localizadas na área comercial, mas que tem gerado alguma contestação, o que parece resultar de reduzida consistência na sua implementação. Por outro lado, o facto de a área comercial já ter realizado algumas experiências neste subsistema dos recursos humanos, tem criado algum mau estar nas outras

232 áreas, sobretudo devido ao facto dos resultados da avaliação poderem estar ligados a sistemas de compensação. Este aspecto foi mesmo apontado como um factor que limita a sinergia entre os diferentes departamentos e conduz muitas vezes a problemas entre as áreas operacionais e comerciais.

Os sistemas de compensação aparentemente são os que têm levantado maior polémica na organização, tendo sido referida a necessidade de existirem políticas globais de remuneração, implementadas com rigor, uniformidade 
e consistência, mas também depois com descentralização das decisões. Isto porque, por um lado, há uma certa consciência de que as propostas para a atribuição de prémios ou para os trabalhadores receberem acima da tabela ou ainda para a antecipação da progressão automática, não eram consubstanciadas em critérios uniformes e rigorosos do ponto de vista técnico e científico; por outro lado, foi bastante salientado o factor burocrático nos processos - que causa dificuldades de implementação ao gestor, tendo sido referido, como exemplo, alguns prémios que já deveriam ter sido pagos há um ano, o que ainda não tinha acontecido porque os papeis andavam de um lado para o outro sem se saber muito bem quem tomaria a decisão de efectuar esse pagamento.

Outra prática que tem criado algumas dificuldades na gestão das pessoas é o problema da mobilidade. Sobre isto observaram-se várias perspectivas que nem sempre caminham no mesmo sentido. Por exemplo, constatou-se que existe alguma percepção de que a empresa deveria caminhar no sentido de aumentar a prática do "outsourcing" e apostar em pessoas com maiores preocupações pelo mercado. Mas isto levanta problemas com os trabalhadores que já existem na empresa, sendo aqui que a mobilidade poderia dar alguma ajuda. Mas também isto pode levantar alguns problemas complicados porque há trabalhadores que possuem determinada categoria profissional que não se adapta à área para onde poderia ir trabalhar; por vezes as funções são completamente diferentes e isso pode levantar questões jurídicas complicadas, conflitos com sindicatos e até tribunais. Isto relaciona-se com um dos factores que parece estar a limitar um maior desenvolvimento da gestão de recursos humanos, que é o facto da empresa viver num enquadramento de acordo colectivo em que a gestão tem um espaço de manobra limitado. Mas ultrapassado este problema, outros se levantam ao nível da mobilidade. Por exemplo, foi referida a dificuldade em recrutar internamente trabalhadores. mesmo noutras áreas da empresa de menor importância estratégica, porque - responsável dessa área pode não deixar sair o profissional. A direcção de recursos humanos foi aqui apontada como tendo um poder de acção limitado, devido à sua insuficiente actuação nestas situações. Aliás, a um nivel mais geral, este estudo começa a evidenciar a existência de uma percepção ineficaz da gestão de recursos humanos, essencialmente devido a estarmos em presença de "um sistema complicado que trata de muitas coisas". Mais, por parte dos profissionais mais directamente envolvidos nas práticas de recursos 
humanos estas percepções não parecem ser muito contrariadas. Os próprios recursos humanos referem que estamos perante uma empresa de grande dimensão, que possui um peso burocrático muito grande, o que tem conduzido, nos últimos anos, a uma actuação muito administrativa e pouco inovadora na área dos recursos humanos. Acrescentam que muitas acções foram desenvolvidas pontualmente consoante as competências da chefia e muitas não tinham a ver com políticas da empresa. Reconhecem também que muitas vezes essas acçōes não obtiveram uma resposta adequada da organizaçāo devido à sua carga burocrática, o que, em consequência, afirmam ter-se vindo a verificar alguma desresponsabilização por parte da gestão de linha, a qual procura apenas cumprir os seus objectivos e não se assume como exercendo uma gestão efectiva dos trabalhadores. Daí o esforço que tem sido feito com o desenvolvimento do projecto das competências.

Em síntese, é claramente evidente aqui uma zona de incerteza ao nível da gestão de determinadas práticas de recursos humanos e onde emergem vários interesses não partilhados, o que nos vai levar, logo que possível, a aprofundar esta reflexão.

O projecto das competências: expectativas e dificuldades de implementação. Expectativas.

Em termos conceptuais, o modelo parece ser globalmente percebido de forma positiva sobretudo ao nivel dos profissionais com responsabilidades de gestão. Embora também tenha sido referida a existência de um simples conhecimento das linhas gerais do projecto, ele foi maioritariamente classificado com atributos positivos. Desde ser uma situação nova que vem efectuar uma revolução total na empresa, ao desenvolvimento de competências para responder à concorrência, até à necessidade de levar as chefias a pensarem mais nos seus colaboradores, a aproximarem-se e a comunicarem mais com eles. Mas também há a percepção de que este poderá ser mais um projecto

234 para ficar na "gaveta", Onde o projecto se reveste de contornos mais negativos é nos trabalhadores mais operacionais (técnicos comerciais entrevistados), que percepcionam o modelo essencialmente como "algo" que lhes está a ser pedido pela organização (aumentar o auto-conhecimento, definir objectivos, mais responsabilidade) e como "algo" vago que ainda não perceberam muito bem o que é. Observou-se aqui um elevado desconhecimento e alguma confusão acerca deste projecto, o que indicia que o processo de 
comunicação e divulgação do mesmo perdeu eficácia a níveis hierárquicos mais baixos. Este aspecto prende-se com a comunicação da mudança do contrato psicológico, ao que já fizemos referência na revisão da literatura e o que, segundo Bower e Siehl (1997) consideram ser um dos desafios chave do futuro da gestão de recursos humanos. Recomendam que a gestão dos recursos humanos trabalhe em primeiro lugar com os gestores de topo no sentido de clarificar o conteúdo óptimo do contrato psicológico, devendo depois ser responsável por o comunicar ou mostrar internamente e de forma consistente a todas as actividades dos recursos humanos, como a avaliação do desempenho e o sistema de recompensas. Como já foi referido, isto parece não estar acontecer neste caso, pelo menos com o sucesso desejado, aos níveis mais baixos da hierarquia. E verifica-se o desenvolvimento de expectativas do tipo "vamos ver o que acontece". Ou seja, parece haver a esperança de que algo irá mudar, não se sabe muito bem o quê, sendo que, essa esperança parece ir diminuindo à medida que se desce na cadeia hierárquica. De qualquer forma há uma ideia, ainda que vaga, da necessidade de mudar a cultura organizacional no sentido deste projecto poder vir a flexibilizar algumas das práticas da gestão de recursos humanos e tornar mais autónoma a gestão das pessoas.

\section{Dificuldades de implementação.}

Como já foi referido, o projecto das competências começou a ser implementado através da formação profissional. Todas as chefias receberam formação sobre o modelo, as fichas a utilizar, os manuais concebidos e a aplicação informática que iria servir de suporte ao desenvolvimento do projecto. Depois da formação, o objectivo era que fossem para os seus locais de trabalho fazer entrevistas aos seus colaboradores, no sentido de identificar competências detidas e acordar com cada colaborador os passos necessários para o desenvolvimento efectivo das competências identificadas pelo modelo na respectiva área funcional. Para os ajudar neste trabalho, foi criada uma estrutura de facilitadores, à qual, mais tarde, as chefias poderiam colocar qualquer duvida que surgisse na realização do trabalho (competências, utilização do "software",etc.) Após a realização das entrevistas, a chefia deveria introduzir a informação recolhida no sistema informático. A quantidade de pessoas que realizasse este trabalho, seria, para os responsáveis do projecto, um dos primeiros indicadores do sucesso da sua implementação. Nessa altura, o objectivo era colocar no sis- 
tema de informação um cadastro mais completo das competências detidas pelos trabalhadores de forma a que pudesse ser feita uma gestão mais adequada dos recursos humanos. Era uma primeira adaptação à matriz das competências onde se pretendia obter um novo desenho dos cursos de formação de forma a aumentar a sua eficácia. Para isso, o modelo começou a fixar objectivos claros e a promover formas alternativas à formação em sala, nomeadamente auto-formação, formação "on job", estágios, etc.

Para conquistar gradualmente $\circ$ envolvimento dos trabalhadores, foi apontado com alguma insistência a necessidade de se começarem a obter alguns resultados práticos na implementação do projecto. Esta também poderá ser uma das razões que conduziu a orientação inicial do projecto para o sistema de formação profissional, visto, por um lado, ser uma prática de recursos humanos que nesta empresa reúne relativos consensos acerca da necessidade em alterar os seus processos e, por outro, não ser normalmente um subsistema "quente" dos recursos humanos nas organizações, como é classificado por Lawler e Ledford Jr (1997). Isto poderá tornar a prática da formação menos crítica e polémica em termos de resistências a alteração de processos e justificar, por isso, que o processo de mudança em curso tenha começado por aí.

Ao nivel das entrevistas efectuadas nas outras áreas funcionais(comercial, infraestruturas) foi referido, de uma maneira geral, a ausência de consequências da implementação do projecto. Ou seja, o modelo parece ainda não ter revelado implicações directas ao nível da mudança nas práticas de recursos humanos, o que parece responder à respectiva questão colocada no início da investigação. Estes resultados são confirmados pelo descontentamento ao nivel da correspondência entre os cursos de formação do manual e as necessidades. Foi mesmo referido que não houve grandes melhorias em relação ao ano passado e que o catálogo de formação parecia bastante semelhante. As diferenças parecem residir no facto de no passado os cursos de formaçāo 236 serem escolhidos pelo próprio a partir de alguns interesses pessoais. enquanto que neste modelo isso não se verifica. Outra dificuldade que foi possivel observar prende-se com a manifesta dificuldade sentida pelas chefias em falar com os colaboradores, tendo emergido a falta de tempo como justificação, embora também se tenham levantado indícios de insuficiente preparação técnica para a realização de entrevistas desta natureza, o que levanta algumas questões sobre a validade das mesmas. Sobre isto, numa das entrevistas 
emergiu a seguinte afirmação: "as pessoas até fizeram as entrevistas, agora duvido que estejam bem feitas porque as pessoas não têm muito tempo nem preparação. Acho que devíamos ter mais apoio nesta área." A própria introdução dos resultados das entrevistas no sistema informático não pareceu efectuar-se de forma pacíica, essencialmente devido a ser "um sistema pouco amigável", como foi apontado. Outro problema observado prende-se com a contenção de custos entretanto definidos pela empresa, o que levou a determinados cortes na formação. Isto parece ter provocado algum descrédito no modelo, sobretudo para com os trabalhadores que já estavam inscritos em cursos de formação.

Em sintese e a partir desta análise, nota-se alguma diferença entre a aceitação global do modelo e a expectativa de obter resultados efectivos. Ou seja, as razões da mudança das práticas de gestão de recursos humanos e a concepção do modelo de gestão por competências não são colocadas em causa, mas ao nível da própria implementação percebeu-se que já são colocadas algumas dúvidas. $E$ estas dúvidas passam também pelo investimento que as pessoas até decidiram fazer no desenvolvimento das suas competências. mas depois questionam-se: "o que é que se ganha em aderir ao modelo?", "como é que isto é compensado?". Como não sentiram respostas claras e pragmáticas a estas perguntas e também por outros factores que entretanto vão acontecendo, como por exemplo os cortes na formação, começa a notarse alguma ruptura com as expectativas criadas à volta do modelo conceptual. Isto levanta-nos a questão da coerência entre a concepção do modelo de gestão por competências e a sua implementação. Será que estão aqui implícitos problemas de validade pragmática? (Santos, 1989). Ou seja, será que se está a falar de coisas distintas em termos da concepçāo e implementação do modelo, realizadas por culturas diferentes(os teóricos e os práticos)? Será que a teoria não está suficientemente sólida e perde, por isso, validade pragmática?

Para além de nos responder à questão da investigação relativa às expectativas e implementação do modelo, estas preocupações irão ser objecto de maior aprofundamento no futuro desenvolvimento deste trabalho, o mesmo acontecendo a outros aspectos que iremos discutir a seguir em jeito de conclusão deste artigo. 


\section{Comentários finais e orientações futuras do estudo de caso}

Os resultados que temos vindo a apresentar, para além de terem já proporcionado o levantamento de questões pertinentes, ainda que de âmbito relativamente específico e às quais já fizemos referência, permitem-nos perceber a um nivel mais geral, que estamos perante questōes directamente relacionadas com o envolvimento e participação dos colaboradores, aliás, uma das questões iniciais deste trabalho. Desde o diagnóstiço efectuado pela organização, em que este problema foi claramente evidente, até à implementação do projecto das competências, o envolvimento, a participação e a motivação dos colaboradores foram variáveis que marcaram sempre presença no desenvolvimento do projecto. Aliás, este é um problema já discutido por March e Simon (1958), quando referem nessa altura que a gestão de recursos humanos estava a preocupar-se com questões relacionadas com a participação e envolvimento dos colaboradores. Como vimos, neste estudo, o envolvimento e relacionamento dos trabalhadores com o projecto é, para os níveis mais baixos, de alguma indiferença. Para os níveis de gestão levantam-se outros problemas, os quais se relacionam com o poder e o relacionamento entre departamentos e entre estes e a direcção de recursos humanos. Foi apontado com alguma frequência a falta de autonomia para tomar determinadas decisões(por exemplo, para premiar um colaborador, para não o deixar sair da empresa, para recrutar internamente noutro departamento, etc.). Essencialmente nesta última decisão é relativamente consensual a necessidade de intervenção pela direcção de recursos humanos de forma a arbitrar este jogo de interesses entre diferentes departamentos. Mas enquanto numas situaçōes a direcção de recursos humanos é solicitada a efectuar uma maior intervenção, noutras situações é apontada como demasiado centralizadora de decisões e ainda noutros contextos não sabem muito bem o que é que ela pode fazer por eles. Aqui foi evidenciada alguma confusão na medida em que, como foi referido, "existem muitas portas de entrada, muitas zonas de interface ao

238 nível da decisão". Ou seja, o envolvimento e a participação a este nível parece sobretudo dependente do poder que o gestor dai pode e espera retirar.

Em síntese, a análise dos dados recolhidos voltam a permitir o levantamento de várias questões pertinentes, nomeadamente indiciam que cada uma das áreas funcionais/departamentos procuram alcançar o seu próprio poder de funcionamento. A ser verdade, e como sugere Gergen(1992), será que ao fazerem isto desenvolvem definições do real e coordenam as suas acções à 
volta dessas definições? E que tipo de relacionamento/articulação existe entre os diferentes departamentos/áreas da empresa? E como são vistas as linguagens dos outros departamentos? Que consequências têm estes isolamentos/ /funcionamentos próprios ou divergências de interesses para a organização como um todo? Será que este modelo vem solicitar uma maior partilha de realidades organizacionais entre sub-unidades dentro da organização? Como é que a organização vai integrar os diferentes interesses dos diversos actores da organização? A partir deste modelo, para onde se dirige a gestão de recursos humanos? Será que o maior ou menor controlo desta divergência de interesses (ou incertezas) é o espaço que legitima e atribui poder à gestão dos recursos humanos na organização?

Estas considerações e questões levantadas, para além de nos terem dado algumas respostas às questōes iniciais da investigação, permitiram orientar este trabalho para novos caminhos sobre os problemas inerentes às práticas da gestão de recursos humanos e gestão por competências.

\section{REFERÊNCIAS}

BARNARD, C.I. (1938). The functions of the Executive. Cambridge, MA: Harvard University Press. BOYATZIS,R.E. (1982). The Competent Manager. A Model for Effective Performance.New YorkWiley-interscience.

BOUWEN, R e STEYAERT, C. (1994).Group Methods of Organizational Analysis. In: Catherne Cassell e Gillian Symons (Eds), Qualitative Methods in Organizational Research, Sage.

BOTERF, G.L (1998). L' ingénierie des compétences. Paris:Editions D 'Organisations.

BOWEN. D. E. e SIEHL. C. (1997). The Future of Hurnan Resource Management: March and Simon (1958) Revisited. In D. Ulich. M. R. Losey e G. Lake. HR Tomorrow's Management: 48 Thought Leaders Call for Change

FEAGIN. J., ORUM, A.e SJOBERG, G. (1990). A cose for cose study. Chapel Hill, NC: University of North Carolina Press.

GERGEN, K.J. (1992). Organization theory in the posmodern era.In M.Reed e M. Hughes (eds),

Rethinking Organization. Londres: Sage, 207-226.

GILLET, P. (1994). La compétence au travail.In Edcation Permanente, $n^{\circ} 135$, Paris: Association Éducation Permanente, p 23-32.

GHISELLI, E.F. (1966).The Validity of Occupational Aptitude Tests. New York John Wiley.

HAMEL, G. (1990). Competition for Competence \& Inter-Partner Learning Within International Strategic Alliances. Strategic Manogement Journal, 12,p. 83-103.

KRUEGER M.A. (1994). Focus Groups a proctical guide for apllied research. Newbury Park, CA: Sage. 
LADO, A.A. e WILSON. M.C. (1994). Human resource systems and sustained competitive advantage: a competency-based perspective. Academy of Manogement Review, 19: 699-727.

LAWLER, EE (1992). The ultimate advantoge: Creating the high-involvement organizotion, . San Francisco: Jossey-Bass

LAWLER. E. E. (1996). From the Ground Up: Six Principles for Creating the New Logic Corporation. San Francisco, CA: jossey-Bass.

LAWLER, E. E. e LEDFORD JR, G. E. (1997). New Approaches to Organizing: Competencies, Capabilities and the Decline of the Bureaucratic Model. In: C.LCooper e S.E. Jackson (Eds), Creating Tomorrow's Organizations. John Wiley.

LEVINSON, H., PRICE, C., MUNDEN, K e SOLLEY, C. (1962). Men, Management mental health. Cambridge, MA: Harvard University Press.

LUCERO. M.A. e ALLEN, RA. (1994). Employee benefits: A growing source of psychological contrct violations. Human Resource Management, 33:425-446.

MCLEAN PARKS, J. e SCHMEDEMANN, D.A. (1994). When promises become contracts: Implied contract and handbook provisions on job security.Human Resource Management 33: 403-423.

MORGAN, D.L. (1991). Focus Groups as Qualitative Research (Qualitative Research Methods Series,vol.16) Bevery Hills, CA: Sage.

MARCH. J.C., e SIMON. H. A. (1958). Organizations. New York Wiley.

MAROY. C. (1995). A análise qualitativa de entrevistas. In L Albarello, F. Digneffe, J.P. Hiemaux, C.Maroy, D. Ruquoy e P.Saint-Georges (Eds), Práticas e métodos de Investigação em Ciências Sociais. Lisboa, Gradiva.

MCCLELLAND. D. (1973). Testing for Competence Rather Than for Intelligence-American Psichologist, volume $28,1-14$

MCCLELLAND, D. (1996). Assessing Competencies: Use of Behovioral Event Interviews to Assess Competencies Associoted with Executive Sucess. Boston:Hay/McBer.

MISCHEL, W. (1966). Personality and Assessment New York Wiley.

ROUSSEAU, D.M. (1989). Psychological and implied contracts in organizations. Employee Responsibilities and Rights journal, 2: $121-139$.

ROUSSEAU, D. M. (1995). Psychological Contracts in Organizations: Understanding Written and Unwritten Agreements. Thousand Oaks. CA: Sage.

ROUSSEAU, D. M. (1996). Changing the deal while keeping the people. In: Academy of Management Executive, Vol. 10. p. 50-59.

SCHEIN, E.H. (1965). Organizational psychology. Englewood Cliffs, N]: Prentice Hall.

STALK, G., EVANS, P.E. e SHULMAN, LE. (1992). Competing on capabilities: The new rules of corporate strategy. Harvard Business Review, 70: 57-69.

SCHULZ.W. C. (1993). Skill-based strategy and entrepre neurial leadership: how individual and corporate entrepreneurs create value (tese de doutoramento nāo publicada). University of Georgia.

SPENCER, L.M. e SPENCER (1993). Competence ot WorkNew York John Wiley Santos,B.S. (1989). Introdução a uma ciência pós-moderna.Porto: Afrontamento

STRAUSS, A. e J.CORBIN (1998). Basics of qualitative research: Techniques and procedures for developing grounded theory. Thousand Oaks, CA:Sage.

ULRICH, D.E LAKE, D. (1990), Organizational Capability. New YorkWiley.

YIN, R (1984). Case Study Research: design and methods. New York: Sage. 
(Página deixada propositadamente em branco) 
Série

Investigação

Coimbra

Imprensa da Universidade

2000 